Article

\title{
Fluorescence Detection of Deoxyadenosine in Cordyceps spp. by Indicator Displacement Assay
}

\author{
Arinta Agnie Dewantari ${ }^{1}$, Nattha Yongwattana ${ }^{1}$, Panwajee Payongsri ${ }^{1}$, Sawinee Seemakhan ${ }^{2}$, \\ Suparerk Borwornpinyo ${ }^{1,2}$, Akio Ojida ${ }^{3}$ and Jirarut Wongkongkatep ${ }^{1, *(D)}$ \\ 1 Department of Biotechnology, Faculty of Science, Mahidol University, Bangkok 10400, Thailand; \\ arinta.agnie@gmail.com (A.A.D.); oun.nattha@gmail.com (N.Y.); panwajee.pay@mahidol.ac.th (P.P.); \\ suparerk.bor@mahidol.ac.th (S.B.) \\ 2 Excellent Center for Drug Discovery, Faculty of Science, Mahidol University, Bangkok 10400, Thailand; \\ sawinee.ecdd@gmail.com \\ 3 Graduate School of Pharmaceutical Sciences, Kyushu University, 3-1-1 Maidashi, Higashi-ku, \\ Fukuoka 812-8582, Japan; ojida@phar.kyushu-u.ac.jp \\ * Correspondence: jirarut.chu@mahidol.ac.th; Tel.: +66-2201-5302
}

Academic Editor: Takahiro Kusukawa

Received: 31 March 2020; Accepted: 26 April 2020; Published: 28 April 2020

\begin{abstract}
A rapid, sensitive and reliable indicator displacement assay (IDA) for specific detection of $2^{\prime}$ - and $3^{\prime}$-deoxyadenosine ( $2^{\prime}$-dAde and $3^{\prime}$-dAde), the latter is also known as cordycepin, was established. The formation of inclusion complex between protonated acridine orange $\left(\mathrm{AOH}^{+}\right)$and cucurbit[7]uril (CB7) resulted in the hypochromic shift of fluorescent emission from $530 \mathrm{~nm}$ to $512 \mathrm{~nm}$. Addition of cordycepin to the highly fluorescent $\mathrm{AOH}^{+} / \mathrm{CB} 7$ complex resulted in a unique tripartite $\mathrm{AOH}^{+} / \mathrm{CB} 7 / \mathrm{d}$ Ade complex with diminished fluorescence, and such reduction in emission intensity serves as the basis for our novel sensing system. The detection limits were 11 and $82 \mu \mathrm{M}$ for $2^{\prime}$ - and $3^{\prime}$-deoxyadenosine, respectively. The proposed method also demonstrated high selectivity toward $2^{\prime}-$ and $3^{\prime}$-deoxyadenosine, owing to the inability of other deoxynucleosides, nucleosides and nucleotides commonly found in Cordyceps spp. to displace the $\mathrm{AOH}^{+}$from the $\mathrm{AOH}^{+} / \mathrm{CB} 7$ complex, which was confirmed by isothermal titration calorimetry (ITC), UV-Visible and proton nuclear magnetic resonance $\left({ }^{1} \mathrm{H}-\mathrm{NMR}\right)$ spectroscopy. Our method was successfully implemented in the analysis of cordycepin in commercially available Ophiocordyceps and Cordyceps supplements, providing a novel and effective tool for quality assessment of these precious fungi with several health benefits.
\end{abstract}

Keywords: cordycepin; fungi; indicator displacement assay; fluorescence; detection; cucurbit uril; acridine orange

\section{Introduction}

Cordycepin, also commonly known as 3'-deoxyadenosine, has gained increasing attention in cancer therapy due to its anti-tumour properties. For instance, it was previously reported that administration of cordycepin to mice with oral cancer can prolong survival and slow down epithelial-mesenchymal transition [1]. In addition, cordycepin was found to trigger apoptosis, leading to reduced proliferation of human lung cancer cell line and gallbladder cancer cells [2,3]. The major sources of cordycepin are Ophiocordyceps and Cordyceps fungi, which have been used for a long time in folk oriental medicine to treat several symptoms including fatigue, respiratory diseases, renal dysfunction, arrhythmias and other heart diseases [4,5]. Several studies have also attested to the pharmacological benefits of Ophiocordyceps and Cordyceps extracts, including antibacterial, anticancer, antifungal, anti-inflammatory, and antioxidant properties [6-8]. 
Capillary electrophoresis, HPLC and LC-MS/MS have been developed for the determination of cordycepin and other nucleosides in Ophiocordyceps and Cordyceps, but they possess drawbacks in terms of separation efficiency for polar compounds [9-13] and produce lots of chemical waste. Recently, a hydrophilic interaction chromatography (HILIC) is coupled with an electrospray ionization tandem mass spectrometry (ESI-MS/MS) was reported for detection of cordycepin [14]. This HILIC ESI-MS/MS method showed high sensitivity, dynamic range, repeatability and recovery relative to routine HPLC. Compared with chromatographic methods, however, fluorescence assays generally allow for superior sensitivity, have rapid and simplified procedures, and generate less chemical wastes.

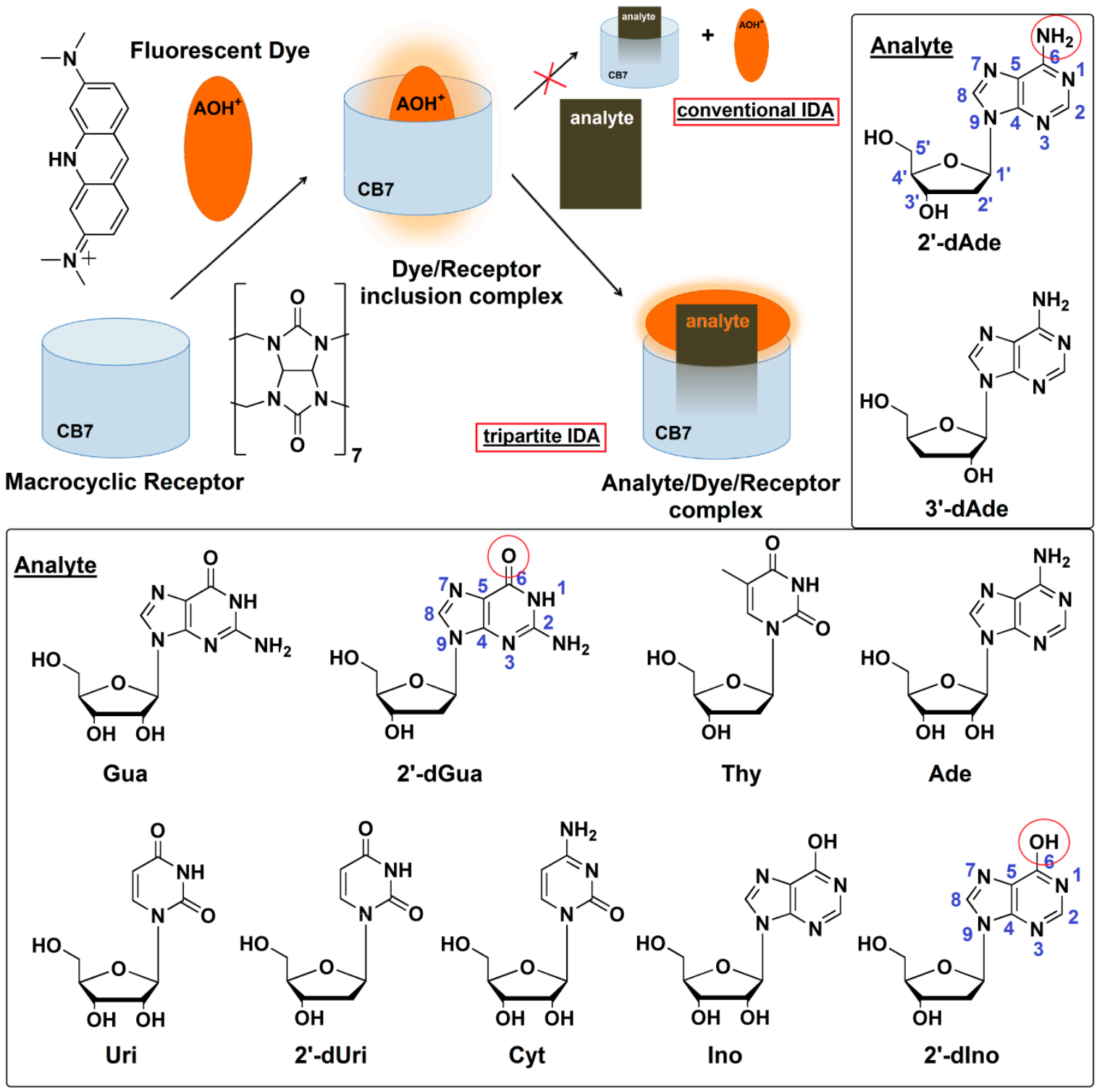

Figure 1. Proposed mechanism of a newly developed tripartite IDA strategy using protonated acridine orange $\left(\mathrm{AOH}^{+}\right)$and cucurbit[7]uril (CB7) based on the transformation from inclusion to Exo complex of $\mathrm{AOH}^{+}$for detection of bioactive nucleosides found in Cordyceps spp. Ade: adenosine, $2^{\prime}$-dAde: $2^{\prime}$-deoxyadenosine, $3^{\prime}$-dAde: $3^{\prime}$-deoxyadenosine or cordycepin, Ino: inosine, $2^{\prime}$-dIno: $2^{\prime}$-deoxyinosine, Gua: guanosine, $2^{\prime}$-dGua: $2^{\prime}$-deoxyguanosine, Uri: uridine, $2^{\prime}$-dUri: $2^{\prime}$-deoxyuridine, Cyt: cytidine, Thy: thymidine.

Indicator displacement assay (IDA) using fluorescent dye is a supramolecular analytical method which employs the concept of "self-molecular recognition" through the supramolecular interactions such as hydrogen bonds, salt bridges, $\pi-\pi$ stacking, van der Waals forces and hydrophobic 
interactions [15]. In a conventional IDA experiment, an indicator is first bound to a receptor, creating the sensing unit. An analyte was introduced subsequently, and then the fluorescence indicator is liberated from the sensing unit (Figure 1). The bound and free fluorescent indicators have different properties, resulting in a signal change in proportion to the concentration of the analyte. The IDA concept was successfully applied for in vitro and in vivo enzymatic assays [16,17]. Herein we report a novel mechanism of tripartite IDA concept based on the transformation of inclusion complex to Exo complex of the indicator/receptor caused by the addition of analyte. The inclusion and Exo complex of the indicator has different fluorescent properties, resulting in a fluorescent change in proportion to the concentration of the analyte as proposed in Figure 1. In this study, a series of cyclodextrins and cucurbit[n] urils was screened for their ability to act as receptors, while a collection of environmental sensitive fluorescent dyes was evaluated for their binding affinity to the chosen receptor, in comparison with the deoxyadenosine. To the best of our knowledge, our study is the first successful case of using IDA for the detection of the bioactive deoxyadenosine and the quantitative analysis of cordycepin in commercially available Ophipcordyceps and Cordyceps products.

\section{Results and Discussion}

\subsection{Selection of a Suitable Dye/Receptor Reporter Pair}

Pairwise combinations of candidate dyes and receptors were tested for their fluorescence properties compared to the uncomplexed counterparts. The receptor candidates comprise a variety of cyclodextrins and cucurbit[n]urils, and the candidates for fluorescent dyes included esculetin, cascade yellow, nonyl acridine orange, berberine (BE), 2-p-toluidinylnaphthalene-6-sulphonate (2,6-TNS) and acridine orange $\left(\mathrm{AOH}^{+}\right)$(see their chemical structures in Supplementary Materials Figure S1). We restricted the candidates to commercially available compounds, to ensure the cost-effectiveness and accessibility of our method. Among cyclodextrins and cucurbit[n]urils tested, cucurbit[7] uril (CB7) showed the highest increase in fluorescence response upon titration to the aqueous solution of the environment-sensitive fluorescent dye (Supplementary Materials Figure S1c). It should be noted that addition of CB7 to the $\mathrm{AOH}^{+}$in $10 \mathrm{mM}$ ammonium acetate at $\mathrm{pH} 4.0$ caused an increase in fluorescence emission by approximately $100 \%$ as well as a hypochromic shift from 530 to $512 \mathrm{~nm}$ (Figure 2a). For free $\mathrm{AOH}^{+}$ under acidic condition, the ratio of $F_{512}$ to $F_{530}$ was 0.59 which then increased to 1.27 and 1.32 upon addition of two and three equivalents of CB7, respectively (Figure 2a inset), which indicated a strong affinity with a binding constant of $1.0 \times 10^{6} \mathrm{M}^{-1}$, as calculated by the least-square curve-fitting method. Shaikh et al. (2008), reported that the cationic $\mathrm{AOH}^{+}$found under acidic condition $(\mathrm{pH}<7)$ can strengthen the binding capacity between $\mathrm{AOH}^{+}$and $\mathrm{CB} 7$ via ion-dipole interactions between the ureido carbonyl rims of CB7 and the charged $\mathrm{AOH}^{+}[18]$. Other dyes such as $\mathrm{BE}$ and 2,6-TNS were also reported to exhibit significant increases in their fluorescent emissions upon binding to CB7 [19,20]. However, BE and 2,6-TNS require the excitation wavelengths of 343 and $328 \mathrm{~nm}$, respectively, which may also induce strong autofluorescence from bright yellow Cordyceps militaris extracts and interfere with the detection. Indeed, we observed that excitation at $375 \mathrm{~nm}$ induced the highest intensity of autofluorescence of Cordyceps militaris centered at $450 \mathrm{~nm}$ (Figure 2b). The excitation beyond $475 \mathrm{~nm}$ yielded almost no autofluorescence as clearly shown in Figure $2 \mathrm{~b}$. Therefore, the $\mathrm{AOH}^{+} / \mathrm{CB}^{\mathrm{complex}}$, which requires the excitation wavelength of $498 \mathrm{~nm}$, was deemed a suitable IDA reporter pair for detection of cordycepin in Cordyceps and Ophiocordyceps products. 
(a)

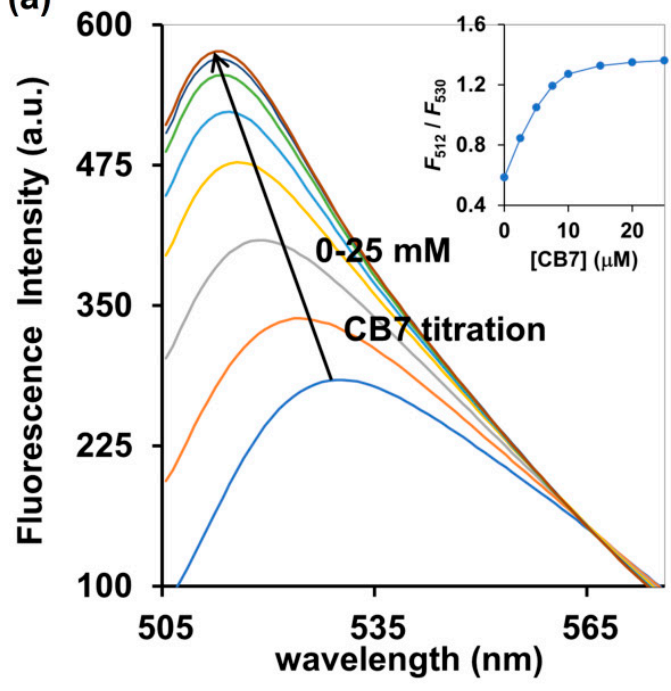

(b)

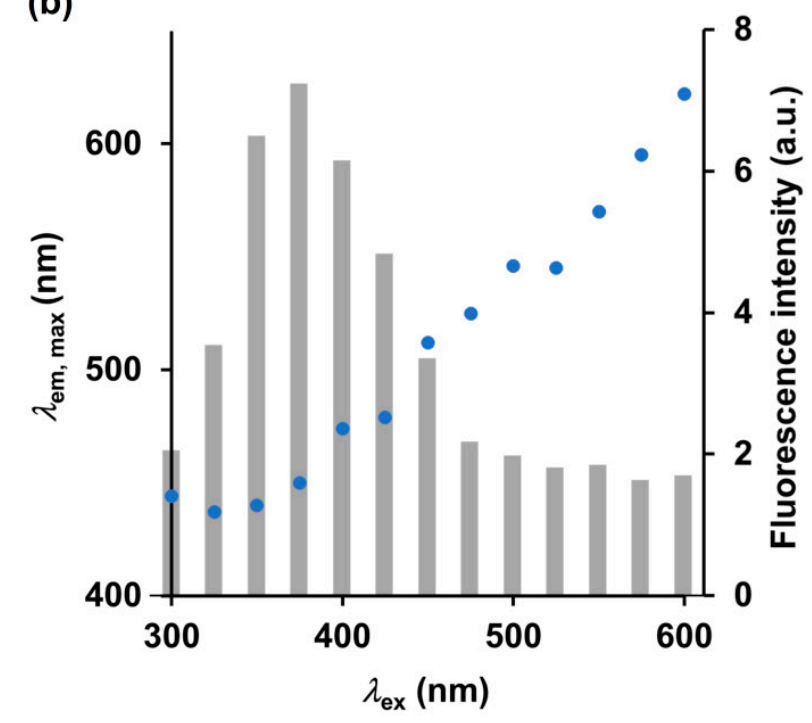

Figure 2. (a) Fluorescence spectrum and (inset) ratiometric change $\left(F_{512} / F_{530}\right)$ of $\mathrm{AOH}^{+}(5 \mu \mathrm{M})$ upon addition of CB7 $(0-25 \mu \mathrm{M})$ in $10 \mathrm{mM}$ ammonium acetate buffer (pH 4.0), $\lambda_{\mathrm{ex}}=498 \mathrm{~nm}$. (b) Autofluorescence of Cordyceps militaris extracts at different excitation wavelengths $\left(\lambda_{\mathrm{ex}}\right)$. The left and right $y$-axes represent the maximum emission wavelength $\left(\lambda_{\mathrm{em}, \max }\right.$, blue circle) and the corresponding fluorescence intensity (gray bar), respectively.

\subsection{Fluorescence Detection of Deoxyadenosine and the Selectivity of IDA}

A salient property of the CB7 macrocycle is its high affinity toward various molecules with $K_{a}$ often in the range of $10^{3} \mathrm{M}-10^{9} \mathrm{M}^{-1}$, compared with cyclodextrin which rarely provides $K_{\mathrm{a}}$ values beyond higher than $10^{3} \mathrm{M}^{-1}$ in aqueous media [19]. CB7 also shows the size and charge selectivity. Based on the inner cavity diameter and height of CB7 is $7.3 \AA$ and $9.1 \AA$, respectively, the cavity volume is approximately $367 \AA^{3}$ [20]. This strict size bestows high selectivity toward specific analytes that can fit in the cavity. Positively charged analytes showed generally higher affinities to CB7 than their non-charged counterparts by a factor of 10-100, due to their ability to form ion-dipole interactions with the carbonyl-fringed CB7 portals [20]. Isothermal titration calorimetry (ITC) suggested the 1:1 binding mode of $\mathrm{CB} 7$ toward $\mathrm{AOH}^{+}$, deoxyadenosines and adenosine. It was also revealed that $\mathrm{CB} 7$ bound $2^{\prime}$-dAde most strongly with the $K_{\mathrm{a}}$ of $5.62 \times 10^{4} \mathrm{M}^{-1}$, while 3- and 7-fold weaker binding was observed for $3^{\prime}$-dAde and Ade, respectively (Table 1 and Supplementary Materials Figure S2). The superior affinity of CB7 toward $2^{\prime}$-and $3^{\prime}$ - dAde relative to Ade may be attributed to the lack of a hydroxyl group at the $\mathrm{C}^{\prime}$ and $\mathrm{C}^{\prime}$, respectively (Figure 1). Other deoxynucleosides, $2^{\prime}$-dIno and $2^{\prime}$-dGua, were also subjected to ITC with CB7, but no heat change was detected, which may be explained by the structural difference between $2^{\prime}$-dAde and these two analogs. In $2^{\prime}$-dAde, a primary amino group is located at $\mathrm{C} 6$ position, while in $2^{\prime}$-dIno this is replaced with a hydroxyl group. Although $2^{\prime}-\mathrm{dGua}$ has an $\mathrm{NH}_{2}$ substituent, it is located at $\mathrm{C} 2$ rather than $\mathrm{C} 6$ (Figure 1). Taken together, the results also suggest that the CB7 prefers binding with adenine over hypoxanthine, guanine and other pyrimidine bearing deoxynucleosides, leading to the preference toward $2^{\prime}$ - and $3^{\prime}$-dAde over 2'-dIno, 2' -dGua and $2^{\prime}$-dUri (Figure 1). By considering the acid-base properties of adenosine and guanosine in aqueous solution, adenosine is in the monoprotonated form with three tautomers at N1, N7 and N3 [21], whereas guanosine exists in the neutral form with two tautomers at N1 and N7 [22]. The preference of CB7 toward deoxyadenosine can be ascribed to the high affinity of CB7 toward the positively charged monoprotonated adenine moiety in water, due to their ability to form ion-dipole interactions with the carbonyl-fringed CB7 portals [20]. The ITC also revealed that the binding affinity of CB7 toward $\mathrm{AOH}^{+}$ was $4.52 \times 10^{3} \mathrm{M}^{-1}$ with hydrophobic interaction as a main driving force. The binding capability of $\mathrm{AOH}^{+} / \mathrm{CB} 7$ was 12.4- and 3.6-fold weaker than $2^{\prime}$-dAde/CB7 and 3'-dAde/CB7, respectively, suggesting 
that both $2^{\prime}$-dAde and $3^{\prime}$-dAde could displace $\mathrm{AOH}^{+}$in the $\mathrm{CB} 7$ cavity. The fluorescence displacement assay was then employed using $\mathrm{AOH}^{+} / \mathrm{CB} 7$ as the reporter pair. Figure 3 showed that the fluorescence emission from the $\mathrm{AOH}^{+} / \mathrm{CB} 7$ complex, relative to the free $\mathrm{AOH}^{+}$control, was reduced to $71 \%$ upon addition of $2^{\prime}$-dAde $(0.9 \mathrm{mM})$ and red-shifted from 512 to $530 \mathrm{~nm}$ (Figure 3a). The percentage of reduction in $F_{512} / F_{530}$ was higher than $50 \%$ in the case of $2^{\prime}$-and $3^{\prime}$-dAde, but the value was diminished to $20 \%$ in the case of Ade. No significant change was observed when Ino, 2'-dIno, Gua, 2'-dGua, Uri, 2'-dUri, Cyt, Thy, ATP, ADP, AMP, inorganic phosphate (Pi), inorganic pyrophosphate (PPi) and purified water was added under the same condition. The fluorescent measurement strongly suggested that the $\mathrm{AOH}^{+} / \mathrm{CB} 7$ reporter pair is highly selective and suitable for the IDA-based detection of $3^{\prime}$-dAde, the bioactive compound in Cordyceps and Ophicordyceps products. Zhang et al. (2015) reported the spectroscopy and molecular modelling studies of the stable inclusion complex of $3^{\prime}$-dAde with $\alpha$-cyclodextrins, and found electrostatic forces and hydrogen bonds to be the major contributors to their binding strength [23], which is in good agreement with what we observed in the dAde/CB7 complex in this study. To the best of our knowledge, our study is the first to investigate and report the high selectivity of CB7 toward both isomers of deoxyadenosine.

Table 1. Thermodynamic parameters of complex formation between $\mathrm{CB} 7$ and guests $\left(\mathrm{AOH}^{+}\right.$and different nucleosides) assessed by isothermal titration calorimeter in $10 \mathrm{mM}$ ammonium acetate buffer $(\mathrm{pH} 4.0)$.

\begin{tabular}{|c|c|c|c|c|c|}
\hline Guest & $K_{\mathrm{a}}\left(\mathrm{M}^{-1}\right)$ & $\Delta \mathrm{H}(\mathrm{kcal} / \mathrm{mol})$ & $\Delta \mathrm{G}(\mathrm{kcal} / \mathrm{mol})$ & $-\mathrm{T} \Delta \mathrm{S}(\mathrm{kcal} / \mathrm{mol})$ & Major Interaction \\
\hline $\mathrm{AOH}^{+}$ & $4.52 \times 10^{3}$ & $15.8 \pm 5.1$ & -4.99 & -20.8 & Hydrophobic \\
\hline $2^{\prime}$-dAde & $5.62 \times 10^{4}$ & $-10.3 \pm 0.2$ & -6.48 & 3.79 & Hydrogen bonding \\
\hline $3^{\prime}$-dAde & $1.64 \times 10^{4}$ & $-12.0 \pm 0.4$ & -5.75 & 6.21 & Hydrogen bonding \\
\hline Ade & $8.06 \times 10^{3}$ & $-8.6 \pm 0.3$ & -5.33 & 3.23 & Hydrogen bonding \\
\hline $\begin{array}{l}2^{\prime} \text {-dIno } \\
2^{\prime}-d G u a\end{array}$ & \multicolumn{5}{|c|}{ No binding observed } \\
\hline
\end{tabular}
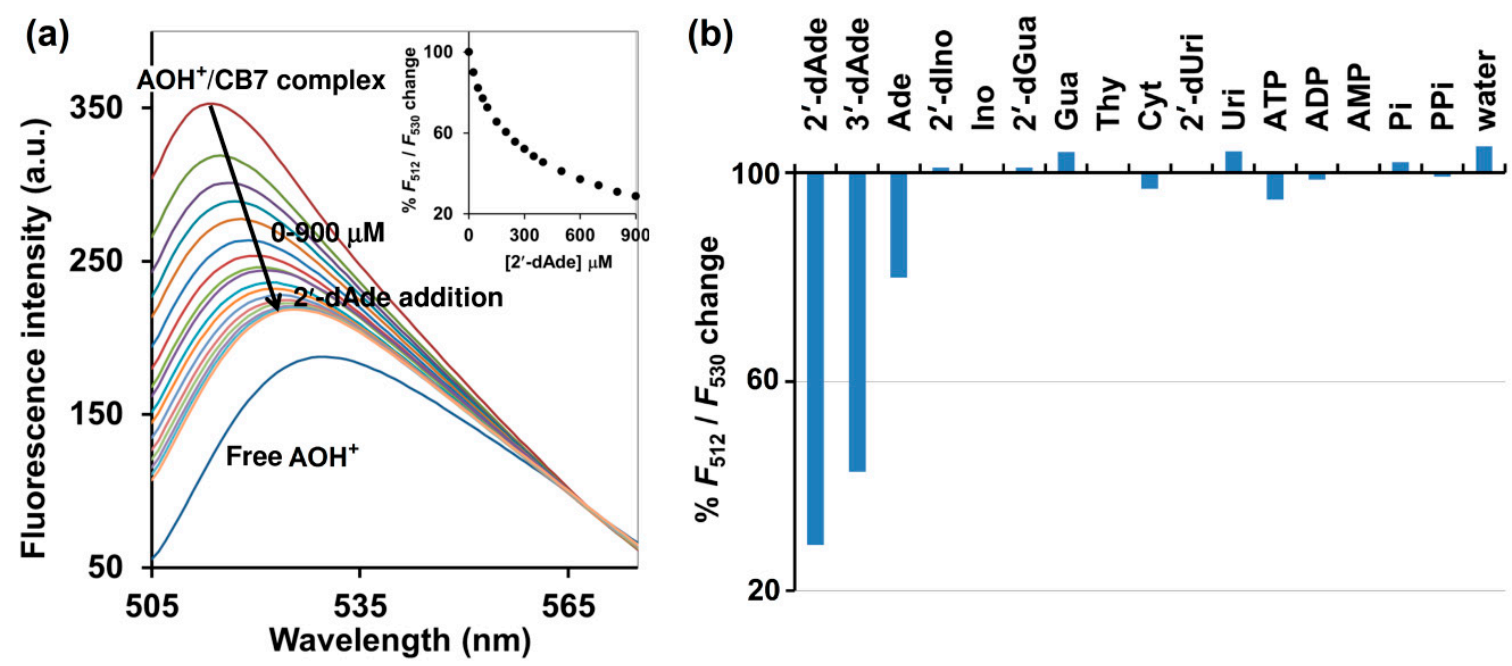

Figure 3. (a) Fluorescence spectrum of $\mathrm{AOH}^{+} / \mathrm{CB} 7$ complex upon addition of various concentrations of $2^{\prime}$-dAde. The percentages of change $\left(F_{512} / F_{530}\right)$ are shown in the inset. $(\mathbf{b}) \%$ change $\left(F_{512} / F_{530}\right)$ of the $\mathrm{AOH}^{+} / \mathrm{CB} 7$ complex upon addition of various analytes at $900 \mu \mathrm{M}$. Measurement condition: $5 \mu \mathrm{M}$ $\mathrm{AOH}^{+}, 10 \mu \mathrm{M} \mathrm{CB7}, 10 \mathrm{mM}$ ammonium acetate buffer (pH 4.0). $\lambda_{\mathrm{ex}}=498 \mathrm{~nm}$. Pi: inorganic phosphate; PPi: inorganic pyrophosphate.

The displacement of $\mathrm{AOH}^{+}$by deoxyadenosine was further investigated using proton nuclear magnetic resonance $\left({ }^{1} \mathrm{H}-\mathrm{NMR}\right)$ and UV-Visible spectroscopy. ${ }^{1} \mathrm{H}-\mathrm{NMR}$ measurement provided an insight to the complexation between $\mathrm{AOH}^{+} / \mathrm{CB} 7,2^{\prime}-\mathrm{dAde} / \mathrm{CB} 7$ and the mixture of $\mathrm{AOH}^{+} / \mathrm{CB}^{\prime} / 2^{\prime}-\mathrm{dAde}$. 
The singlet peak at $2.8 \mathrm{ppm}\left(\mathrm{H}_{1}\right)$ corresponds to the methyl group of the $\mathrm{AOH}^{+}$that became broad after complexation with CB7 as shown in Figure $4 \mathrm{~b}, \mathrm{c}$. The two protons at H3' of $2^{\prime}$-dAde also merged and broadened, while the two singlet peaks of the adenine ring $\left(\mathrm{H}_{1^{\prime}}-\mathrm{H}_{2^{\prime}}\right)$ collapsed into one singlet peak after complexation with CB7 (Figure 4e,f). However, the mixture of $\mathrm{AOH}^{+} / \mathrm{CB}^{2} / 2^{\prime}-\mathrm{dAde}$ yielded another unique spectrum which did not show any signs of free $\mathrm{AOH}^{+}$(Figure $4 \mathrm{~d}$ ). Although further investigations in detail are required for structural elucidation of the host-guest interactions in the tripartite complex of $\mathrm{AOH}^{+} / \mathrm{CB} 7 / 2^{\prime}$-dAde, it was clear that $\mathrm{AOH}^{+}$was partially displaced, but not as a free molecule. The possibility of Exo complex formation between $\mathrm{AOH}^{+} / \mathrm{CB}$ and $\mathrm{AOH}^{+} /$sulfobutylether- $\beta$-cyclodextrin was suggested by Liu et al. (2009) and Sayed et al. (2017) [24,25]. In this study, the formation of Exo complex with $2^{\prime}$-dAde/CB7 may explain the fate of $\mathrm{AOH}^{+}$after moved from the CB7 cavity (Figure $4 \mathrm{~d}$ ). They also reported that the Exo complex of $\mathrm{AOH}^{+} / \mathrm{CB}^{\mathrm{did}}$ not yield a strong fluorescence emission as observed in the case of inclusion complex [25], therefore transformation from an inclusion to Exo complex of $\mathrm{AOH}^{+} / \mathrm{CB} 7$ in the presence of deoxyadenosine enabling the unique fluorescent detection of deoxyadenosine using $\mathrm{AOH}^{+} / \mathrm{CB} 7$ reporter pair.

(a) CB7

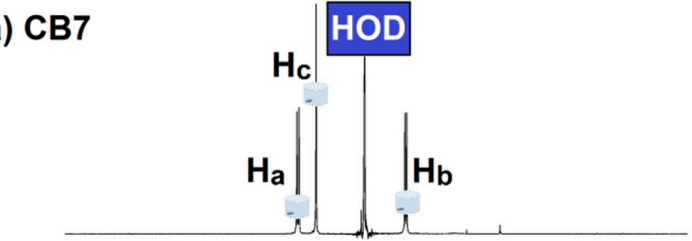

(b) $\mathrm{AOH}^{+}$

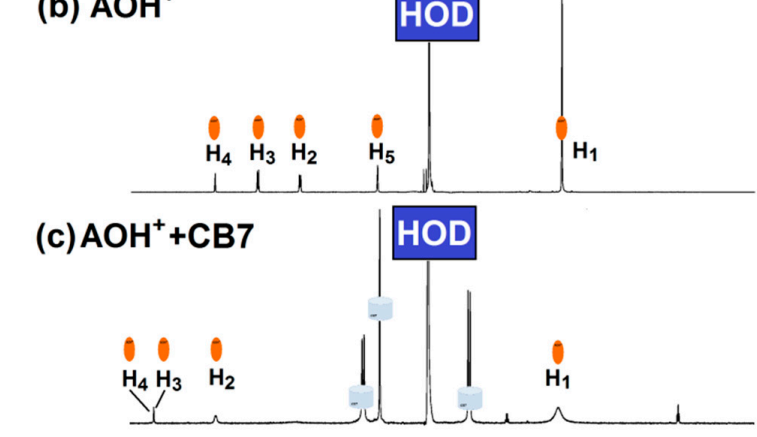

(d) $\mathrm{AOH}^{+}+\mathrm{CB} 7+2$ '-dAde

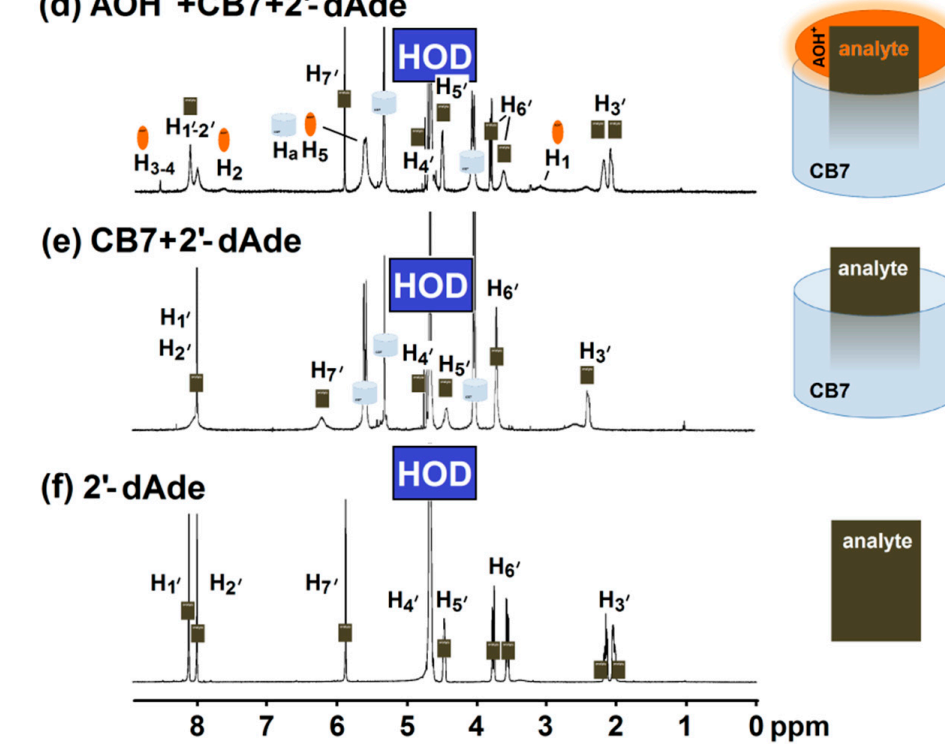

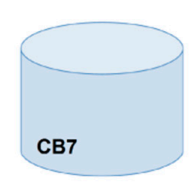
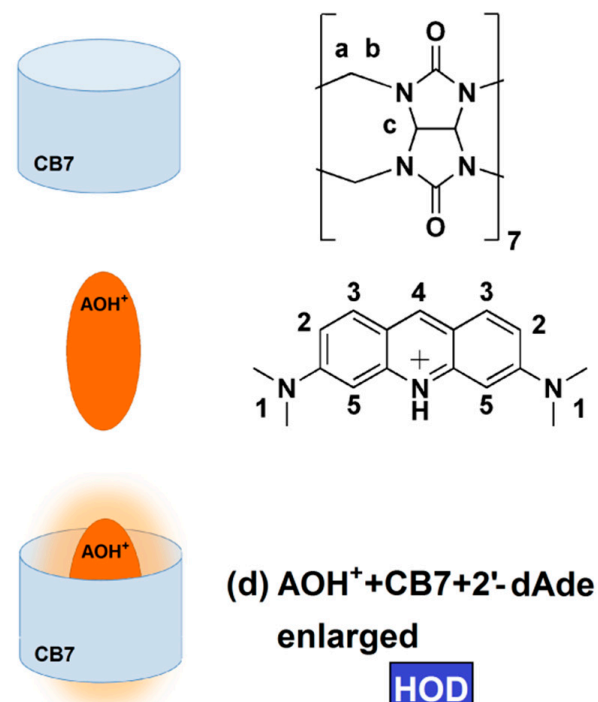

(d) $\mathrm{AOH}^{+}+\mathrm{CB} 7+2$ - -dAde enlarged
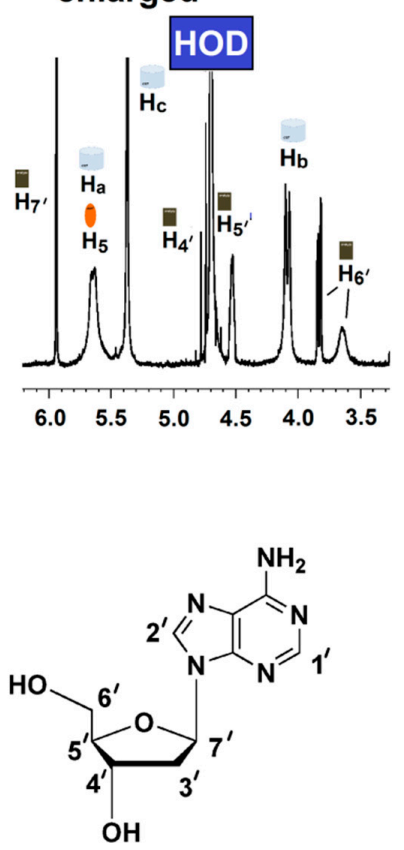

Figure 4. Proton nuclear magnetic resonance (400 MHz, $\left.\mathrm{D}_{2} \mathrm{O}\right)$ spectrum of (a) CB7 (4 mM); (b) AO $(2 \mathrm{mM})$; (c) mixture of AO (2 mM) and CB7 (4 mM); (d) mixture of AO (4 mM), CB7 (4 mM) and 2' -dAde $(4 \mathrm{mM})$; (e) mixture of CB7 (4 mM) and 2'-dAde (4 mM); (f) 2'-dAde (20 mM). 
UV-Visible spectroscopy analysis confirms that the free CB7, 2'-dAde and the CB7/2'-dAde complex do not have any absorbance beyond $300 \mathrm{~nm}$, while the free $\mathrm{AOH}^{+}$displays a strong absorbance centered at $498 \mathrm{~nm}$ (Figure 5a). The complex formation between the $\mathrm{AOH}^{+}$and $\mathrm{CB} 7$ increased the absorbance at $483 \mathrm{~nm}$ sharply with the two isosbestic points at 452 and $502 \mathrm{~nm}$ upon addition of CB7 to the $\mathrm{AOH}^{+}$in $10 \mathrm{mM}$ ammonium acetate buffer solution (pH 4.0) (Figure 5b). However, the addition of $2^{\prime}$-dAde to $\mathrm{AOH}^{+} / \mathrm{CB} 7$ did not reverse the $\mathrm{UV}-\mathrm{Vis}$ spectrum of $\mathrm{AOH}^{+} / \mathrm{CB} 7$ to the free $\mathrm{AOH}^{+}$, but only the slight intensity reduction and blue shift of the $\lambda_{\max }$ from 483 to $476 \mathrm{~nm}$ after addition of $2^{\prime}$-dAde were observed (Figure $5 c$ ). This result agrees well with the ${ }^{1} \mathrm{H}-\mathrm{NMR}$ spectrum that $2^{\prime}$-dAde could not liberate the AO from the CB7 cavity, but instead spurred the formation of a three-component $\mathrm{AOH}^{+} / \mathrm{CB} 7 / 2^{\prime}$-dAde complex.

(a)
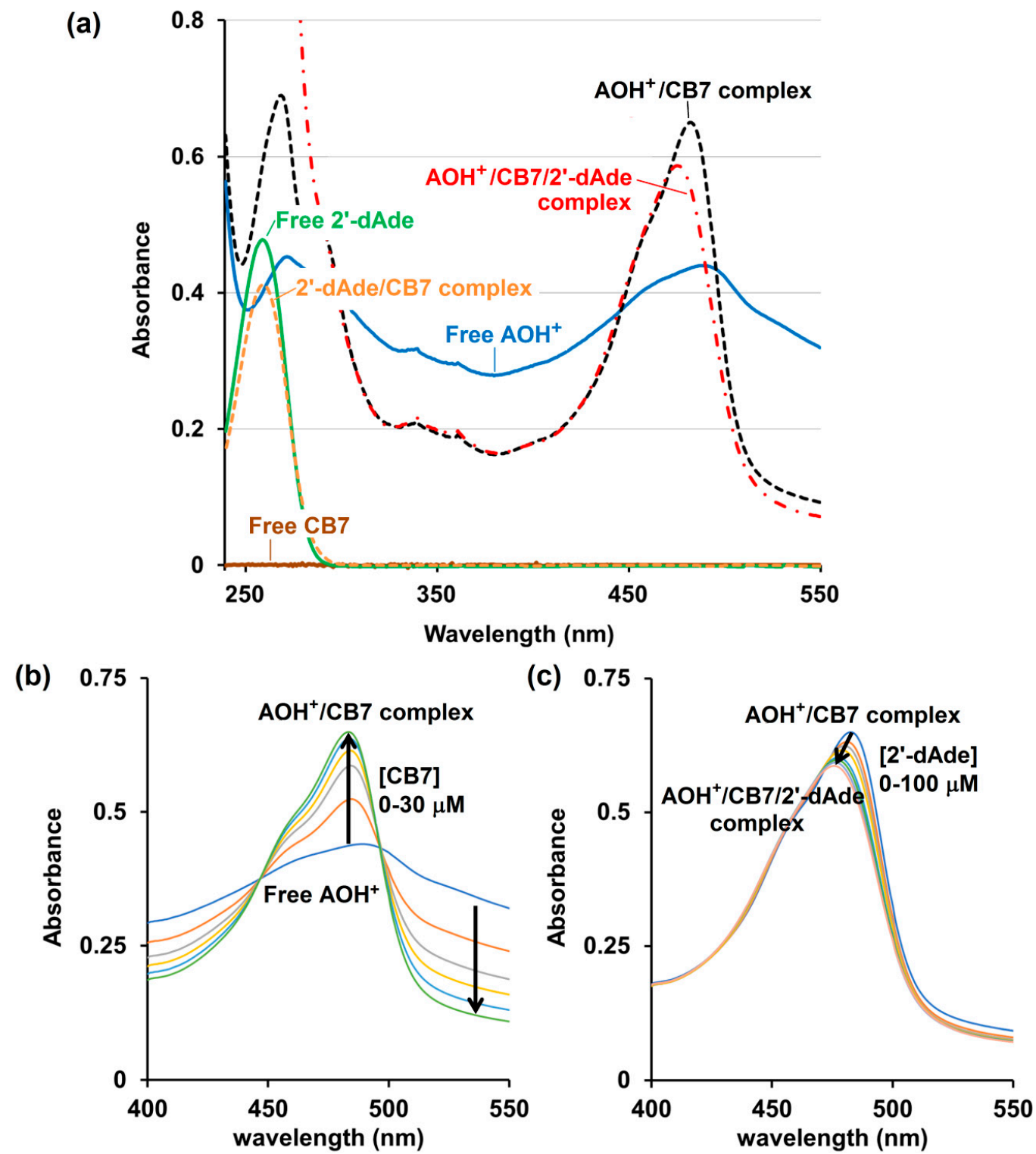

Figure 5. UV-Visible spectrum (JASCO V-530, $10 \mathrm{mM}$ ammonium acetate buffer, $\mathrm{pH}$ 4.0) of (a) free CB7 $\left(10 \mu \mathrm{M}\right.$, solid brown line), free protonated acridine orange $\left(\mathrm{AOH}^{+}, 10 \mu \mathrm{M}\right.$, solid blue line), free $2^{\prime}$-deoxyadenosine (2'-dAde, $30 \mu \mathrm{M}$, solid green line), $2^{\prime}$-dAde/CB7 complex (30/30 $\mu \mathrm{M}$, respectively, orange dash line), $\mathrm{AOH}^{+} / \mathrm{CB} 7$ complex $(10 / 30 \mu \mathrm{M}$, respectively, black dash line $)$ and $\mathrm{AOH}^{+} / \mathrm{CB} 7 / 2^{\prime}$-dAde complex $\left(10 / 30 / 100 \mu \mathrm{M}\right.$, respectively, red dash dot line); (b) $\mathrm{AOH}^{+}(10 \mu \mathrm{M})$ after being titrated with CB7 and (c) addition of $2^{\prime}$-dAde to the $\mathrm{AOH}^{+} / \mathrm{CB} 7$ complex $(10 / 30 \mu \mathrm{M}$, respectively). 
For comparison, the ${ }^{1} \mathrm{H}-\mathrm{NMR}$ spectrum of $2^{\prime}$-dIno and CB7 was obtained and shown in Supplementary Materials Figure S3. The ${ }^{1} \mathrm{H}-\mathrm{NMR}$ spectrum of $2^{\prime}$-dIno and CB7 demonstrated that both $2^{\prime}$-dIno and CB7 existed in the free forms, without any interaction with each other. The ${ }^{1} \mathrm{H}-\mathrm{NMR}$ result also corroborated the ITC and fluorescence measurements that CB7 exhibited a strong binding affinity toward deoxyadenosine over other deoxynucleosides, nucleosides and nucleotides.

We concluded that the detection of deoxyadenosine using $\mathrm{AOH}^{+} / \mathrm{CB} 7$ reporter pair based on the tripartite IDA principle demonstrated a high selectivity, thus suitable for the determination of the bioactive deoxyadenosine in Cordyceps and Ophiocordyceps products.

\subsection{Fluorescence Detection of Deoxyadenosine in Commercially Available Cordyceps and Ophiocordyceps Products Based on Tripartite IDA}

Addition of an aqueous extract of the commercially available Cordyceps and Ohiocordyceps products to the $\mathrm{AOH}^{+} / \mathrm{CB} 7$ inclusion complex resulted in fluorescent quenching accompanied by the red shift from 512 to $530 \mathrm{~nm}$ (Figure 6a). This suggests that cordycepin present in the sample could switch the $\mathrm{AOH}^{+}$molecule from an inclusion complex to the Exo complex, as also demonstrated by ${ }^{1} \mathrm{H}-\mathrm{NMR}$ and UV-Vis spectroscopy. The fluorescence change $\left(F_{512} / F_{530}\right)$ was linearly correlated with the amount of cordycepin spiked, with the $\mathrm{R}^{2}>0.99$ (Figure $6 \mathrm{~b}$ ). The concentrations of cordycepin determined by HPLC were slightly lower than the values obtained from our IDA method, but both still exhibited some agreement despite the large variety of ingredients in the commercially available Cordyceps and Ophiocordyceps products (Figure 6b inset). Taken together, the bioactive cordycepin with several reported health benefits can be evaluated in commercial Cordyceps and Ohiocordyceps products using tripartite IDA with $\mathrm{AOH}^{+} / \mathrm{CB} 7$ as a reporter pair in $10 \mathrm{mM}$ ammonium acetate buffer $(\mathrm{pH} 4.0)$ as an approximate analysis. Besides its rapidity, the newly developed IDA method is also environmentally-friendly because it produced less chemical wastes - the volume of each assay is limited to only $3 \mathrm{~mL}$, in contrast to conventional HPLC techniques which demand large amounts of mobile phase for column conditioning, sample elution, and post-assay column cleaning [26]. The method will be highly suitable for quality control of the Cordyceps and Ohiocordyceps commercial products, especially in the production line.
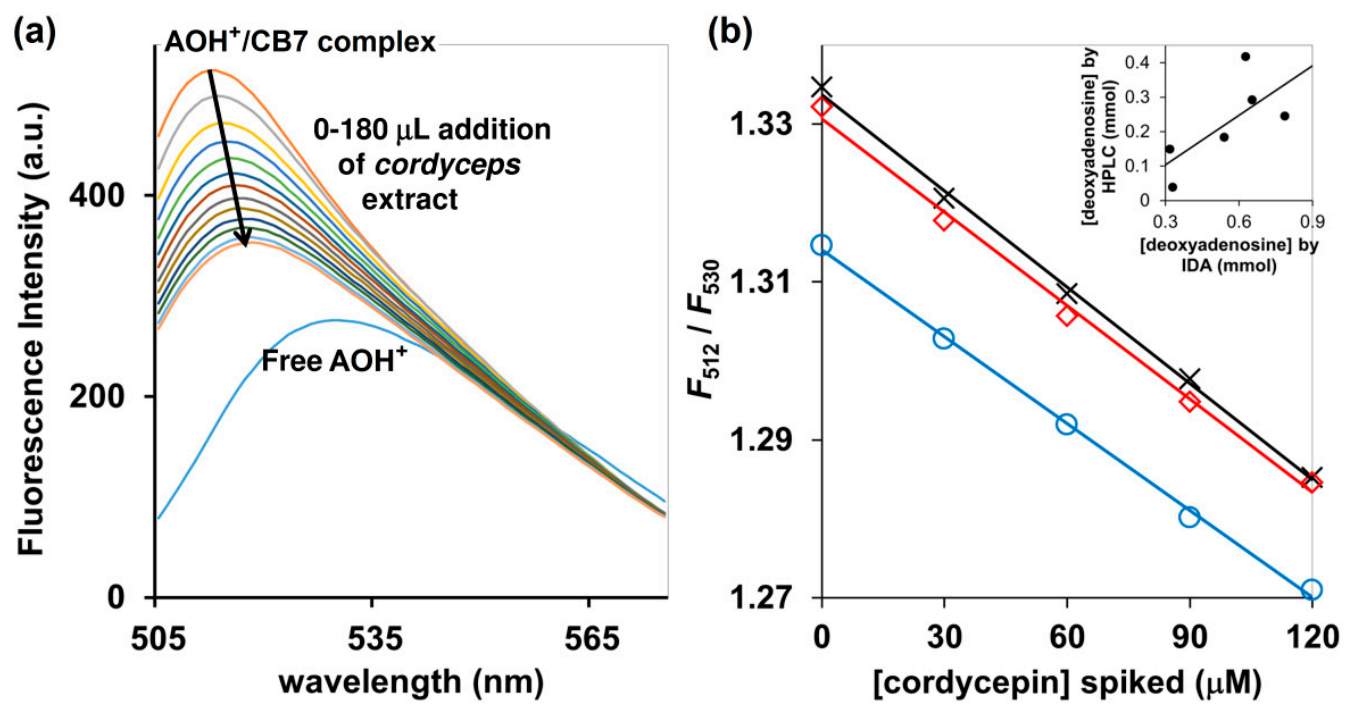

Figure 6. (a) Fluorescence detection of deoxynucleosides in Ophiocordyceps and Cordyceps commercial products using $\mathrm{AOH}^{+} / \mathrm{CB} 7$ as a reporter, performed in $10 \mathrm{mM}$ ammonium acetate buffer ( $\mathrm{pH}$ 4.0); (b) $F_{512} / F_{530}$ of $\mathrm{AOH}^{+} / \mathrm{CB} 7$ complex upon addition of Ophiocordyceps and Cordyceps product number 1 (blue circle), number 2 (red square) and number 3 (black cross), all of which had been spiked with cordycepin; (inset) relative concentrations of deoxynucleotides determined by HPLC and tripartite IDA proposed in this study. 
In summary, we reported the highly selective deoxyadenosine detection based on IDA, using $\mathrm{AOH}^{+} / \mathrm{CB} 7$ as a reporter. Addition of cordycepin to the highly fluorescent $\mathrm{AOH}^{+} / \mathrm{CB} 7$ complex resulted in a unique tripartite $\mathrm{AOH}^{+} / \mathrm{CB} / \mathrm{d}$ Ade complex with diminished fluorescence, and such reduction in emission intensity serves as the basis for our novel sensing system. Although the developed tripartite IDA system is already quite specific to deoxyadenosine, our research group is currently working toward achieving better differentiation between the 2'-dAde and $3^{\prime}$-dAde, and between the bioactive cordycepin and adenosine, in order to improve the accuracy of cordycepin quantification in the commercial Cordyceps and Ophiocordyceps products even further.

\section{Materials and Methods}

\subsection{Chemicals}

Chemicals and reagents used in this study were of analytical grade or higher. Ammonia solution, glacial acetic acid, and HPLC grade acetonitrile were purchased from Merck, Darmstadt, Germany. Sodium dihydrogen orthophosphate and sodium hydroxide were obtained from Ajax Finechem Pty Ltd., Auckland, New Zealand. Cyclodextrins, cordycepin, 2'-deoxyguanosine, uridine, and 2'-deoxyadenosine were commercially available from Wako Pure Chemical Industry, Ltd., Osaka Japan. Sodium pyrophosphate decahydrate, adenosine $5^{\prime}$-triphosphate disodium salt (ATP), adenosine $3^{\prime}$-monophosphate (AMP), adenosine $5^{\prime}$-diphosphate disodium (ADP), adenosine, and cucurbit[n]urils were obtained from Sigma-Aldrich Co. St. Louis, MO, USA. Cytidine, 2'-deoxyuridine, inosine, thymidine, and 2'-deoxyinosine were purchased from FUJIFILM Wako Pure Chemical Corporation, Japan. Guanosine was obtained from Alfa Aesar, Thermo Fisher Scientific, Heysham, UK. Acridine orange $(\mathrm{AO})$ and berberine $(\mathrm{BE})$ was purchased from Invitrogen Company, Eugene, Oregon, OR USA. Deionized water was prepared using a Millipore Milli Q-Plus system (Millipore, Bedford, MA, USA). Deuterium oxide $\left(\mathrm{D}_{2} \mathrm{O}\right)$ was purchased from Cambridge Isotope Laboratories, Inc., Tewksbury, MA, USA.

\subsection{Spectroscopy}

To a solution of $10 \mathrm{mM}$ ammonium acetate buffer $\mathrm{pH} 4.0(3 \mathrm{~mL})$, the stock solution of the fluorescent dye was added and then the fluorescence emission was measured by a spectrofluorometer (JASCO FP6500, Tokyo, Japan). A receptor was serially titrated to the dye solution until the saturation of fluorescence emission was observed. The procedure was repeated by varying the receptors and dyes. The autofluorescence of the $C$. millitaris extract, which appears as a bright yellow color, was evaluated by measuring the fluorescence emission spectrum of the extract at the excitation wavelength between $300-600 \mathrm{~nm}$.

A stock solution of deoxyadenosine and other deoxynucleoside and nucleoside was added serially to the solution of $10 \mathrm{mM}$ ammonium acetate buffer $\mathrm{pH} 4.0(3 \mathrm{~mL})$ containing $5 \mu \mathrm{M}$ acridine orange and $10 \mu \mathrm{M}$ CB7. The fluorescence spectrum was then recorded by a spectrofluorometer (JASCO FP6500, Tokyo, Japan). The analysis of Ophiocordyceps and Cordyceps samples was conducted under similar condition. UV-Visible spectrum was recorded using a JASCO V-530 (Tokyo, Japan). ${ }^{1} \mathrm{H}-\mathrm{NMR}$ spectrum was acquired on Bruker Ascend ${ }^{\mathrm{TM}} 400$ (Bruker BioSpin, Billerica, Massachusetts, MA USA).

\subsection{Isothermal Titration Calorimetric (ITC) Analysis}

Acridine orange, cordycepin, adenosine, $2^{\prime}$-deoxyadenosine and $2^{\prime}$-deoxyinosine were set as titrands whereas the CB7 solution was used as a titrant. The measurement was performed in Microcal PEAQ-ITC (Malvern Instrument, Malvern, UK). The sample cell was loaded with $0.5 \mathrm{mM} \mathrm{CB7,} \mathrm{while}$ the reference cell was filled with $10 \mathrm{mM}$ ammonium acetate buffer solution $\mathrm{pH}$ 4.0. The syringe was filled with $5 \mathrm{mM}$ titrand solution. Microcal PEAQ-ITC Analysis Software was used to analyze calorimetric data for elucidation of binding mechanism and the value of association constant. 


\subsection{Samples Preparation, Extraction and HPLC Analysis}

Commercially available Cordyceps and Ohiocordyceps products were dried at $60^{\circ} \mathrm{C}$ for $24 \mathrm{~h}$. All samples were ground into powder (approximately 50 meshes). Then $1.0 \mathrm{~g}$ of sample was weighed and added to $20 \mathrm{~mL}$ of deionized water. The sample mixture was placed into an ultrasonic bath for $2 \mathrm{~h}$. After extraction, the extract was cooled down to the room temperature, then centrifuged at $18,225 \times g$ (WiseSpin CF-10, Daihan Scientific, Gangwon, Korea) for $5 \mathrm{~min}$ to obtain the clear supernatant. The supernatant was filtered through $0.45 \mu \mathrm{m}$ Supor ${ }^{\circledR}$ Membrane, Acrodisc ${ }^{\circledR}$ syringe filters before analysis. The HPLC analysis was conducted according to Ip et al. (1985) with slight modifications [27]. HPLC analysis of all samples was carried out using a Waters 600 HPLC system equipped with a C-18 reverse phase ODS column (Zorbax ODS, $4.6 \mathrm{~mm} \times 250 \mathrm{~mm}, 5 \mu \mathrm{m}$ ). Isocratic elution was carried out by using $0.1 \mathrm{M}$ triethyl ammonium acetate (TEAA) pH 7.1/acetonitrile (98/2 v/v) as the mobile phase at a flow rate of $1.0 \mathrm{~mL} / \mathrm{min}$. Sample injection volume was $10 \mu \mathrm{L}$. The detection was done at $254 \mathrm{~nm}$ using a photo-diode array detector (Waters 996).

Supplementary Materials: The following are available online at http:/www.mdpi.com/1420-3049/25/9/2045/s1, Figure S1: Chemical structures of macrocyclic receptors (a) and fluorescent dyes (b) tested in this study; (c) Fluorescent response of the dye without $\left(F_{0}\right)$ and with 5 equivalent molar of $\beta$-CD (white) and CB7 (gray) in $10 \mathrm{mM}$ ammonium acetate buffer ( $\mathrm{pH}$ 5.0); Figure S2: ITC analysis (MicroCal PEAQ-ITC, Malvern Instrument, $\mathrm{UK})$ of $\mathrm{CB} 7(0.5 \mathrm{mM})$ and $(\mathbf{a}) \mathrm{AOH}^{+}(4 \mathrm{mM}),(\mathbf{b}) 2^{\prime}$-deoxyadenosine $(5 \mathrm{mM})$ and (c) $3^{\prime}$-deoxyadenosine $(5 \mathrm{mM})$ in $10 \mathrm{mM}$ ammonium acetate buffer ( $\mathrm{pH} 4.0$ ); Figure S3: ${ }^{1} \mathrm{H}-\mathrm{NMR}$ (Bruker Ascend ${ }^{\mathrm{TM}} 400, \mathrm{D}_{2} \mathrm{O}$ ) of the (a) CB7 $(4 \mathrm{mM}),\left(\right.$ b) 2'-deoxyinosine $(4 \mathrm{mM})$ and (c) the mixture between $2^{\prime}$-deoxyinosine and CB7 (4 mM each).

Author Contributions: Conceptualization, J.W.; methodology, J.W. and P.P.; validation, J.W.; formal analysis, A.A.D. and J.W.; investigation, A.A.D., N.Y. and S.S.; resources, J.W., S.B. and A.O.; data curation, A.A.D. and J.W.; writing-original draft preparation, J.W.; writing—review and editing, J.W. and A.O.; Supervision, J.W. and A.O.; project administration, J.W.; funding acquisition, J.W. All authors have read and agreed to the published version of the manuscript.

Funding: This research was funded by the Thailand Research Fund and the Faculty of Science, Mahidol University, grant number IRG5980001. A.A.D. and N.Y. are grateful to Scholarship for Talented Students, Faculty of Science, Mahidol University. Central Instrument Facility (CIF), Faculty of Science, Mahidol University is acknowledged for the instrumental usage grant.

Conflicts of Interest: The authors declare no conflict of interest.

\section{References}

1. Su, N.W.; Wu, S.H.; Chi, C.W.; Liu, C.J.; Tsai, T.H.; Chen, Y.J. Metronomic cordycepin therapy prolongs survival of oral cancer-bearing mice and inhibits epithelial-mesenchymal transition. Molecules 2017, $22,629$. [CrossRef] [PubMed]

2. Wang, Z.; Wu, X.; Liang, Y.N.; Wang, L.; Song, Z.X.; Liu, J.L.; Tang, Z.S. Cordycepin induces apoptosis and inhibits proliferation of human lung cancer cell line H1975 via inhibiting the phosphorylation of EGFR. Molecules 2016, 21, 1267. [CrossRef] [PubMed]

3. Wang, X.A.; Xiang, S.S.; Li, H.F.; Wu, X.S.; Li, M.L.; Shu, Y.J.; Zhang, F.; Cao, Y.; Ye, Y.Y.; Bao, R.F.; et al. Cordycepin induces S phase arrest and apoptosis in human gallbladder cancer cells. Molecules 2014, 19, 11350-11365. [CrossRef] [PubMed]

4. Zhao, J.; Xie, J.; Wang, L.Y.; Li, S.P. Advanced development in chemical analysis of Cordyceps. J. Pharm. Biomed. Anal. 2014, 87, 271-289. [CrossRef]

5. Phan, C.W.; Wang, J.K.; Cheah, S.C.; Naidu, M.; David, P.; Sabaratnam, V. A review on the nucleic acid constituents in mushrooms: Nucleobases, nucleosides and nucleotides. Crit. Rev. Biotechnol. 2018, 38, 762-777. [CrossRef]

6. Qin, P.; Li, X.; Yang, H.; Wang, Z.Y.; Lu, D. Therapeutic potential and biological applications of cordycepin and metabolic mechanisms in cordycepin-producing fungi. Molecules 2019, 24, 2231. [CrossRef]

7. Wong, Y.Y.; Moon, A.; Duffin, R.; Barthet-Barateig, A.; Meijer, H.A.; Clemens, M.J.; de Moor, C.H. Cordycepin inhibits protein synthesis and cell adhesion through effects on signal transduction. J. Biol. Chem. 2010, 285, 2610-2621. [CrossRef] 
8. Cunningham, K.G.; Manson, W.; Spring, F.S.; Hutchinson, S.A. Cordycepin, a metabolic product isolated from cultures of Cordyceps militaris (Linn.) Link. Nature 1950, 166, 949. [CrossRef]

9. Rao, Y.K.; Chou, C.H.; Tzeng, Y.M. A simple and rapid method for identification and determination of cordycepin in Cordyceps militaris by capillary electrophoresis. Anal. Chim. Acta 2006, 566, 253-258. [CrossRef]

10. Wang, Z.; Li, N.; Wang, Y.; Du, L.; Ji, X.; Yu, A.; Zhang, H.; Qiu, F. Simultaneous determination of nucleosides and their bases in Cordyceps sinensis and its substitutes by matrix solid-phase dispersion extraction and HPLC. J. Sep. Sci. 2013, 36, 2348-2357. [CrossRef]

11. Guo, F.Q.; Li, A.; Huang, L.F.; Liang, Y.Z.; Chen, B.M. Identification and determination of nucleosides in Cordyceps sinensis and its substitutes by high performance liquid chromatography with mass spectrometric detection. J. Pharm. Biomed. Anal. 2006, 40, 623-630. [CrossRef] [PubMed]

12. Hu, H.; Xiao, L.; Zheng, B.; Wei, X.; Ellis, A.; Liu, Y.M. Identification of chemical markers in Cordyceps sinensis by HPLC-MS/MS. Anal. Bioanal. Chem. 2015, 407, 8059-8066. [CrossRef] [PubMed]

13. Xie, J.W.; Huang, L.F.; Hu, W.; He, Y.B.; Wong, K.P. Analysis of the main nucleosides in Cordyceps sinensis by LC/ESI-MS. Molecules 2010, 15, 305-314. [CrossRef] [PubMed]

14. Zhao, H.Q.; Wang, X.; Li, H.M.; Yang, B.; Yang, H.J.; Huang, L. Characterization of nucleosides and nucleobases in natural Cordyceps by HILIC-ESI/TOF/MS and HILIC-ESI/MS. Molecules 2013, 18, 9755-9769. [CrossRef]

15. You, L.; Zha, D.; Anslyn, E.V. Recent Advances in Supramolecular Analytical Chemistry Using Optical Sensing. Chem. Rev. 2015, 115, 7840-7892. [CrossRef]

16. Hennig, A.; Bakirci, H.; Nau, W.M. Label-free continuous enzyme assays with macrocycle-fluorescent dye complexes. Nat. Methods 2007, 4, 629-632. [CrossRef]

17. Norouzy, A.; Azizi, Z.; Nau, W.M. Indicator displacement assays inside live cells. Angew. Chem. Int. Ed. 2015, 54, 792-795. [CrossRef]

18. Shaikh, M.; Mohanty, J.; Singh, P.K.; Nau, W.M.; Pal, H. Complexation of acridine orange by cucurbit[7]uril and $\beta$-cyclodextrin: Photophysical effects and pK a shifts. Photochem. Photobiol. Sci. 2008, 7, 408-414. [CrossRef]

19. Dsouza, R.N.; Pischel, U.; Nau, W.M. Fluorescent dyes and their supramolecular receptor/guest complexes with macrocycles in aqueous solution. Chem. Rev. 2011, 111, 7941-7980. [CrossRef]

20. Sinn, S.; Biedermann, F. Chemical sensors based on cucurbit[n]uril macrocycles. Isr. J. Chem. 2018, 58, 357-412. [CrossRef]

21. Kapinos, L.E.; Operschall, B.T.; Larsen, E.; Sigel, H. Understanding the acid-base properties of adenosine: The intrinsic basicities of N1, N3 and N7. Chem. Eur. J. 2011, 17, 8156-8164. [CrossRef]

22. Jang, Y.H.; Goddard, W.A.; Noyes, K.T.; Sowers, L.C.; Hwang, S.; Chung, D.S. pKa values of guanine in water: Density functional theory calculations combined with Poisson-Boltzmann Continuum-Solvation model. J. Phys. Chem. B 2003, 107, 344-357. [CrossRef]

23. Zhang, J.Q.; Wu, D.; Jiang, K.M.; Zhanga, D.; Zheng, X.; Wan, C.P.; Zhu, H.Y.; Xie, X.G.; Jin, Y.; Lin, J. Preparation, spectroscopy and molecular modeling studies of the inclusion complex of cordycepin with cyclodextrins. Carbohydr. Res. 2015, 406, 55-64. [CrossRef] [PubMed]

24. Liu, J.; Jiang, N.; Ma, J.; Du, X. Insight into unusual downfield NMR shifts in the inclusion complex of acridine orange with cucurbit[7]uril. Eur. J. Org. Chem. 2009, 29, 4931-4938. [CrossRef]

25. Sayed, M.; Jha, S.; Pal, H. Complexation induced aggregation and deaggregation of acridine orange with sulfobutylether- $\beta$-cyclodextrin. Phys. Chem. Chem. Phys. 2017, 19, 24166-24178. [CrossRef] [PubMed]

26. Christian, G.D. Analytical Chemistry, 5th ed.; John Wiley \& Sons: Hoboken, NJ, USA, 1994; pp. 540-545.

27. Ip, C.Y.; Ha, D.; Morris, P.W.; Puttemans, M.L.; Venton, D.L. Separation of nucleosides and nucleotides by reversed-phase high-performance liquid chromatography with volatile buffers allowing sample recovery. Anal. Biochem. 1985, 147, 180-185. [CrossRef]

Sample Availability: Samples of the cucurbit[7]uril and acridine orange are commercially available. 